\title{
Modo borderline e mundo do trabalho: um ensaio sobre implicações e perspectivas atuais
}

\section{The borderline case and the working world: an essay on consequences and perspectives}

\author{
Kamila Ferreira Marinho \\ Centro Universitário Metodista do IPA. Curso de Psicologia. Porto \\ Alegre, RS, Brasil. \\ E-mail: kamila-marinhoळhotmail.com

\section{Cleber Gibbon Ratto} \\ Centro Universitário La Salle. Porto Alegre, RS, Brasil. \\ E-mail: cgratto®hotmail.com
}

\section{Correspondência}

Av. Guilherme Schell, 5168, ap. 405. Centro, Canoas, RS, Brasil. CEP 92310-022.

\section{Resumo}

Partindo do pressuposto de que o modo borderline parece constituir uma nova "normalidade" atualmente, este artigo busca discutir a sociedade contemporânea em seus modos de vida e o impacto sobre o mundo do trabalho. A busca constante pelo sucesso e pela realização profissional atravessa, consequentemente, as relações de trabalho, que constituem o sujeito. Não há tempo para vazios! É preciso produzir. Considera-se para a discussão o que chamamos de "modo borderline", pensado a partir de sua dimensão fenomenológica e não estrutural, portanto, não a partir do paradigma da psicopatologia individual, mas como sintoma da cultura, em uma sociedade marcada pela impulsividade, fragilidade dos laços sociais e pela chamada "cultura do narcisismo". Através de uma abordagem psicanalítica e com breve descrição da evolução dos modos de trabalho e produção ao longo dos anos, propõe-se uma discussão a respeito dessas novas configurações de vida implicadas no mundo do trabalho, pensando, sobretudo, em como se dá essa relação na contemporaneidade, em pleno capitalismo flexível.

Palavras-chave: Borderline; Trabalho; Capitalismo Flexível; Subjetividade. 
Abstract

Assuming that the borderline case seems to be a new "normality" today, this article discusses the contemporary society in its ways of life and the impact on the working world. The constant search for success and achievement consequently go through labor relations, which constitute the subject. No time for leisure! We have to produce. For the discussion we considered what we call "borderline case", elaborated from its phenomenological and non-structural dimension, and from the paradigm of individual psychopathology, but as a symptom of the culture in a society marked by impulsiveness, fragility of social bonds and the so-called "culture of narcissism". Through a psychoanalytic approach and brief description of the development of working methods and production over the years, we proposed a discussion of these new life dynamics involved in the working world, thinking, above all, in how this relationship is constructed in contemporaneity, in the context of a flexible capitalism.

Keywords: Borderline; Work; Flexible Capitalism; Subjectivity.

\section{Introdução}

Este trabalho tem o intuito de discutir as atuais configurações e necessidades do mundo do trabalhoversus a cultura contemporânea em seus modos de vida.

0 ponto de partida é pensar o trabalho como um dos pilares da constituição subjetiva, da formação do sujeito adulto, e desse modo discutir o quanto nossos modos de viver e de sofrer são úteis às novas configurações do chamado "capitalismo flexível" (Sennett, 2009).

O modo borderline será aqui apresentado não exatamente a partir do Transtorno de Personalidade Borderline (TPB), enquanto categoria nosológica psiquiátrica, mas levando em conta as características de uma sociedade que se organiza e funciona com base em marcas culturais bastante peculiares: sentimento de vazio existencial, impulsividade, busca constante por novas e excitantes experiências, e demandas narcísicas, que resultam numa compulsiva busca por reconhecimento a partir do outro. A isso, alguns autores têm denominado "ampliação do espectro borderline", o que poderia estar constituindo uma nova forma de "normalidade" (Armony, 2010).

Estima-se, segundo Linehan (2010), que 11\% de todos os pacientes psiquiátricos ambulatoriais e $19 \%$ dos pacientes psiquiátricos internados preencham critérios para o TPB. Entre pacientes com alguma forma de transtorno da personalidade, 33\% dos pacientes ambulatoriais e $63 \%$ dos internados parecem preencher critérios para o referido transtorno. Esses números demonstram o crescimento da identificação de características desse espectro na sociedade contemporânea, e isso certamente não se restringe aos pacientes identificados. Durante esta discussão, a expressão "modo borderline” irá referir-se a um espectro amplo de características, e não apenas ao classificado transtorno de personalidade.

Ainda assim, partiremos da descrição nosológica, conforme a Classificação Internacional de Doenças - CID-1o (WHO, 1993), para nos aproximarmos da fenomenologia convencional da personalidade emocionalmente instável, do tipo borderline. Segundo a CID-10, as principais características desse tipo de personalidade são: instabilidade emocional, sentimentos crônicos de vazio, impulsividade, dependência afetiva e a consequente busca de evitar 
o abandono, além de autoagressividade. Importa-me destacar que tais características, longe de representarem um conjunto típico de traços de uma personalidade rara, são cada vez mais frequentes na sociedade contemporânea, tanto nas relações pessoais quanto nas de trabalho.

Quanto às novas configurações do mundo do trabalho, elas oferecem, além de oportunidades sedutoras de flexibilidade, a promessa de ascensão profissional como premiação do esforço individual, o trabalho em home office, as demandas de transformação ininterrupta e a “oportunidade” (obrigatória) de aprimoramento, sempre pautadas pela desempenho do trabalhador, com base em suas competências e habilidades pessoais. Ao mesmo tempo, essas novas configurações são fortemente marcadas pela ansiedade e pelo medo da perda do emprego, o que frequentemente faz que os trabalhadores abram, literalmente, as portas de casa para o trabalho: não se pode perder tempo! As pessoas, então, passam a trabalhar praticamente em tempo integral e suas vidas se organizam em torno disso.

Segundo Sennett (2009), é bastante natural que a flexibilidade cause ansiedade, pois as pessoas não sabem que riscos serão compensados nem que caminhos devem seguir. Esse mundo do trabalho, tão desejado pela ampla maioria, vem constantemente com a promessa de ser flexível: flexível nos horários, nas relações e nas hierarquias. A promessa é bastante sedutora, mas o que aqui desejamos examinar é exatamente o custo de tais transformações e sua possível sintonia com aquilo que denominamos "modo borderline" de vida e sofrimento.

Será aqui discutido um mundo (e um modo) do trabalho onde a fenomenologia borderline está bastante presente, não como um traço psicopatológico, mas muitas vezes como características "interessantes", em determinada medida, para a maioria das empresas e dos empregadores. No entanto, tais características podem não contribuir em nada para um psiquismo sadio e uma vida com sentido. Se o trabalho é um dos pilares fundamentais da nossa cultura e se a sociedade encaminha-se para um funcionamento afetivo e social (e não mais normoneurótico) característico do modo borderline, nossa discussão, portanto, é pertinente.

A proposta é problematizar um tema bastante atual: uma sociedade e um mundo de trabalho onde é necessário produzir, (des)adaptar-se constantemente, render e conquistar reconhecimento compulsivamente. A sociedade contemporânea, nos termos do mundo do trabalho e do funcionamento psíquico, em quase nada se parece com a sociedade que predominou até os anos 1970. Novas formas de organização e de gestão do trabalho coexistem com novas configurações subjetivas, coincidentes no momento cultural de sua emergência: que modos de vida e de sofrimento daí podem derivar?

Para a escrita deste trabalho foi escolhida a forma do ensaio, especialmente pela possibilidade de reinventar, refletir e discutir a prática da escrita e do próprio pensamento. Assim, este ensaio está dividido em três grandes blocos: o primeiro discute o modo borderline de vida e de sofrimento, articulando-o com as características de nossa cultura; o segundo apresenta o mundo do trabalho desde suas formas mais tradicionais de organização e funcionamento até as formas atuais, caracterizadas pela "flexibilização" neoliberal; e o terceiro constitui-se como uma seção que discute as implicações e perspectivas desses dois fenômenos - a ampliação do espectro borderline e as mudanças no mundo do trabalho - para, com isso, pensar o lugar do psicólogo no âmbito da promoção da saúde e da prevenção de doenças do trabalhador, especialmente em relação à população jovem.

\section{O ensaio como estratégia de pesquisa e pensamento}

Encontrei em Larrosa (2004) a curiosa e provocativa afirmação de que o ensaio tem algo relativo à suspensão do juízo, uma atitude de abertura sensível ao fenômeno para sua compreensão, considerando o papel constitutivo de sentido exercido pela própria linguagem. Assim, ensaiar implica assumir a indissociabilidade entre o pensamento, a escrita e a vida. Essa perspectiva está ligada a uma atitude metodológica de caráter fenomenológico, em que o saber não resulta de uma objetivação do problema, tema ou questão de estudo, mas de sua demarcação, desdobramento, exploração pela consciência e pela sensibilidade do pesquisador, num exercício exploratório e descritivo. 
É sabido que o ensaio é considerado como um híbrido entre a filosofia e a literatura. Sua vontade de verdade o habilita como filosófico, e a sua vontade de estilo, como literário. Entretanto, no ensaio, tanto a verdade como o estilo são inseparáveis do sujeito e são inseparáveis da vida, da invenção e da experimentação de possibilidades de vida, de formas de vida, de estilos de vida (Larrosa, 2004, p. 40).

Essa zona de fronteira entre a Filosofia e a Literatura parece ser bastante potente para a experimentação do pensamento na Psicologia. Para explorar o tema relativo ao mundo do trabalho e as configurações psicossociais da cultura contemporânea, utilizarei o ensaio como forma de escrita e problematização. Os escritos de Michel Foucault tinham esse formato, e foi baseado nisso que Jorge Larrossa (2004), em uma conhecida conferência, discutiu as características dessa forma de escrita e pensamento a partir do pensador francês.

E agora que me tornei maior continuo com isso do ensaiar e do ensaiar-se, mas de outra forma, girando em torno da experiência na leitura e na escrita, elaborando a relação entre experiência e subjetividade, e entre experiência e pluralidade, tentando problematizar as três maiores linguagens da experiência: o poema, a narrativa e o ensaio (Larrosa, 2004, p. 5).

Essa imagem, particularmente, - "uma linguagem da experiência” - é o que melhor traduz o motivo da minha escolha: a possibilidade de pensar o mundo do trabalho e suas implicações, além de trazê-las para a discussão a partir de um campo de visão pessoal. A intenção é poder colocar problemas, levantar questões, abrir o pensamento a partir do que me toca a sensibilidade, como trabalhadora, como estagiária e como estudante. Não busco aqui encontrar respostas definitivas, mas principalmente propor novos questionamentos e encontrar bons problemas para seguir pensando.

Segundo Larrossa (2004), há tantos ensaios quanto ensaístas, já que o ensaio é justamente a forma não regulada da escrita e do pensamento, em sua forma mais variada, mais criativa e implicada. Nesse sentido, a busca é também a de me aventurar na escrita, construir um problema e implicar-me em sua exploração, atitude que julgo muito pertinente à formação de uma psicóloga, já que marca essa abertura sensível ao mundo, às questões que pedem passagem, que assediam o pensamento e provocam o exercício constante da análise e problematização das condições de existência.

O ensaio também é, mesmo que de outra forma, palavra no tempo, pensamento no tempo. Poderíamos dizer que o ensaísta pensa e escreve sabendo-se mortal, sabendo que tanto suas palavras como suas ideias são mortais e que, talvez por isso, estão vivas (Larrosa, 2004, p. 33).

Escrever, implicada com a própria experiência, e ao mesmo tempo pensar que essas palavras podem não estar mais vivas: esta possível efemeridade, esta maior liberdade na exposição das ideias, esta necessidade de desnaturalizar o que nos parece comum é o que mais me provoca à construção desta escrita como ensaio; saber-me finita, submetida ao tempo e colocar a subjetividade à prova.

\section{o modo borderline}

"O mundo contemporâneo é impaciente. A sociedade tem pavor de resultados em longo prazo. Este éo quadro da contemporaneidade, a busca constante de conquistas e da satisfação imediata.”

Nise da Silveira

Para seguir este ensaio, é importante destacar aqui quais os traços que caracterizam o modo borderline, para posteriormente relacionar esse modo às relações da vida atual e ao mundo do trabalho.

No início dos estudos da psicanálise, Freud analisou a sociedade da época como predominantemente neurótica. Esta sociedade era marcada, sobretudo, por mecanismos de repressão e recalque, e tinha mecanismos de socialização e de regulação social muito bem configurados: o casamento, a educação, as igrejas e os rituais são exemplos clássicos disso. O mal-estar na civilização consistia basicamente na troca da liberdade (para satisfação dos impulsos) pela promessa de segurança. 
O casamento, a religião, a honra, a honestidade, o amor, tudo está em questão, nada é fixo ou estável. A solidão humana se acentua. Quem sou eu não é uma pergunta abstrata; "to be or not to be" torna-se uma questão cotidiana, e não simples fala teatral (Hegenberg, 2013, p. 18).

No entanto, na contemporaneidade, percebemos uma condição emergente, em que a busca desenfreada pelo gozo ${ }^{1}$ constante se sobrepõe à vontade de segurança, o que faz que os mecanismos repressivos cedam lugar a uma crescente excitação. Conforme a citação de Hegenberg (2013), já não há papéis préestabelecidos; é preciso buscar e saber prontamente quem se é. O sujeito então, de acordo com os modos de vida, deve buscar a constante de satisfação e realização dos desejos. Assim, em lugar das funções repressivas e sublimatórias das culturas tradicionais, a cultura atual opera por incitação ao gozo, mecanismo amplamente capitalizado pela lógica do consumo.

Conforme Minerbo (2013), viemos sob um laço social muito mais frágil que aqueles encontrados em sociedades tradicionais. E isso opera tanto como possibilidade de abertura e criatividade, quanto de desestabilização e perda de referências. Trata-se da chamada "pós-modernidade".

Convencionou-se chamar de pós-modernidade ao momento da história da civilização em que as grandes instituições que serviram de base para a civilização ocidental entram em crise. A falência do modelo único pode ser vivida como libertação, mas também como falta de chão. O laço simbólico, que "soldava" um significante a um significado, tornou-se frágil e corrediço. Com isso, os sentidos se relativizaram [...]. A vantagem é que a fragilidade do símbolo pode ser aproveitada de forma criativa para que novos laços simbólicos sejam constituídos: as pessoas podem se reinventar. Há espaço para que novas formas de viver se tornem possíveis, contemplando a singularidade do desejo (Minerbo, 2013, p. 32).

Assim, aquilo que há bem pouco tempo poderia ser interpretado apenas como fragilidade, impotên- cia ou decadência cultural, abre-se também como uma possibilidade (nunca garantida) de reinvenção de nossos modos de vida e convivência.

Conforme Armony (2010), o "Borderline Normal" pode ser considerado um homem da pós-modernidade por sua inquietude, flexibilidade, criatividade, sensibilidade, permeabilidade e intuição; pela sua apreensão mais direta, menos mediada da realidade, pela sua capacidade de detectar os mínimos movimentos do inconsciente pessoal, coletivo e cultural.

Armony (2010) diferencia os tipos de borderline, referindo-se ao "borderline normal" e "borderline pesado". O borderline pesado seria aquele constituído por um modo patológico de funcionamento, com suas emoções e controles bastante desorganizados. Armony (2013b) caracteriza-o como pesado, polissintomático e com dificuldades nas relações pessoais por sua fragmentação ou por suas necessidades narcísicas exacerbadas. É possível pensar que este seria o borderline a quem se aplicaria o diagnóstico de Transtorno de Personalidade Borderline.

No entanto, num instigante exame das condições culturais da atualidade, o autor aponta para a emergência de um novo tipo: o "borderline normal" - segundo ele, um tipo bastante característico do mundo contemporâneo.

O borderline normal constituiria uma "identificação em devir" (Armony, 2010, p. 65), um modo de funcionamento menos estável, e por isso mesmo com muitas potencialidades a serem aproveitadas, como por exemplo, a capacidade de ser mais permeável às afecções, às intensidades. Nesse caso, não estamos tratando de uma estrutura perversa ou de um funcionamento limítrofe em termos psicodinâmicos. Esse será o perfil com o qual estabeleço a discussão neste ensaio, e o que temos identificado mais frequentemente na sociedade contemporânea.

A grosso modo pode-se dizer que durante aproximadamente os primeiros 50 anos de psicanálise o neurótico domina a cena psicanalítica e que, de lá para cá, as chamadas síndromes limítrofes têm ocupado um lugar cada vez maior na clínica e no pensamento psicanalítico (Armony, 2013c, p. 1).

Segundo Roudinesco e Plon (1998), o termo em uma dimensão hedonista tornou-se sinônimo de prazer, alegria, bem-estar e volúpia. 
Armony (2010) busca trazer à tona os motivos pelos quais considera o modo borderline uma nova normalidade. Psicanaliticamente, o que se esperava anteriormente era que um paciente após um tratamento, por exemplo, pudesse seguir sua vida, sem a ajuda e o acompanhamento de um analista. A normalidade estava em buscar (ainda que não se pudesse atingir completamente) a superação da neurose.

Em seus livros e artigos, Armony discute a possibilidade de conceber o borderline não como um sujeito que fica na linha de borda entre a psicose e a neurose, mas como alguém que vive em uma "outra" normalidade. "Até pouco tempo a psicanálise tinha como sustentáculo de ideal de normalidade exclusivamente o neurótico: quanto menos neurótica, mais a pessoa se aproximaria deste ideal de normalidade" (Armony, 2010, p. 110). É nesse sentido que esta discussão será conduzida: entendendo o borderline como um sujeito que também produz, e que, diga-se de passagem, representa muito os modos de vida na contemporaneidade.

Segundo Arós e Vaisberg (2009), a sociedade voltada para o consumo transforma as pessoas em mercadorias, tanto nas transações do mercado de produtos e serviços quanto no que se refere ao mercado de trabalho, no qual o objeto a ser comercializado são os próprios seres humanos.

Essas novas configurações subjetivas estão inscritas e agenciadas pela chamada "sociedade do risco" (Giddens; Beck; Lash, 1997; Giddens, 1991), uma forma de funcionamento social pautada pela exposição a condições extremas de competição e promessas sedutoras de gozo que geram um estado constante de alternância entre a superexcitação e o medo.

Conforme Figueiredo (2007, p. 84), do ponto de vista subjetivo,

Observa-se a irrupção de uma forte angústia existencial: o "sinal de angústia" pode se tornar ininterrupto, o que o desqualifica para as funções de ativação de defesas egoicas e tende a torná-lo um desorganizador do funcionamento psíquico de indivíduos e coletividades; o pânico em forma latente ou manifesta ocupa um lugar importante na vida emocional contemporânea e pode irromper pelos mais diversos incidentes, alastrando-se de forma rápida e incontrolável.
Em sintonia com essa perspectiva, Bauman também aponta para condições político-subjetivas bastante semelhantes, ao referir-se à "sociedade do medo" em que vivemos.

As oportunidades de ter medo estão entre as poucas coisas que não se encontram em falta nesta época, altamente carente em matéria de certeza, segurança e proteção. Os medos são muitos e variados. Pessoas de diferentes categorias sociais, etárias e de gênero são atormentadas por seus próprios medos; há também aqueles que todos nós compartilhamos - seja qual for a parte do planeta em que possamos ter nascido ou que tenhamos escolhido (ou sido forçados a escolher) para viver (Bauman, 2008, p. 31).

Esse misto de risco e medo, que abala nossa segurança ontológica (confiança na continuidade da existência) caracteriza, na atualidade, não apenas um espectro psicopatológico específico, como é o caso do borderline, mas um modo de vida que se alastra no tecido social, entre os "normais". Trata-se de um novo modo de subjetivação, que expressa e ao mesmo tempo constrói novos valores, práticas e sentimentos. "O medo é reconhecidamente o mais sinistro dos demônios que se aninham nas sociedades abertas de nossa época. Mas é a insegurança do presente e a incerteza do futuro que produzem e alimentam o medo mais apavorante e menos tolerável" (Bauman, 2007, p.32).

Buscamos, sobretudo, pensar - seja sobre a sociedade, seja sobre o sujeito -, além de alguém que sofre, alguém que produz e é produzido, que se beneficia, mas também é "usado" pela cultura em que se insere. Segundo Armony (2010), de qualquer forma, além do sofrimento "psiquiátrico" classificável, precisamos também enxergar no borderline um modo particular de estar no mundo.

Ao examinar as características que definem nosologicamente uma pessoa com Transtorno de Personalidade Borderline, podemos verificar muitas características recorrentes nos sujeitos da contemporaneidade. Sentimentos crônicos de vazio, respostas emocionais reativas, necessidade de satisfação imediata, instabilidade nos relacionamentos interpessoais e impulsividade; medo constante e sensação aguda de risco à manutenção de sua in- 
tegridade física ou psíquica; traços identificados em boa parte da população e muitas vezes (assustadoramente) considerados traços "desejáveis" para enfrentar os desafios da atualidade, confundindo-se com uma condição "necessária” para defender-se das pressões do mundo e conviver com elas.

$\mathrm{Na}$ contemporaneidade, observamos sujeitos que passam a vida buscando preencher um vazio, alterando, repetidas vezes, trabalhos e cursos, e, no entanto, quando se percebem ao cabo de suas intermináveis tentativas, sentem-se vazios: vazios de sentido no que estudam ou no que trabalham. Muitas dessas pessoas parecem não encontrar um sentido para toda a rapidez de troca e busca de experiências.

Conforme Arós e Vaisberg (2009), queixas como as citadas anteriormente estão cada vez mais frequentes nos serviços de saúde mental e nos consultórios particulares, embora Winnicott, desde 1963, já afirmasse ironicamente não haver mais neuróticos disponíveis para tratamento psicanalítico na Inglaterra.

Após essa aproximação sobre uma "nova normalidade" borderline, seguiremos para o próximo capítulo buscando compreender como o mundo do trabalho modificou-se ao longo dos anos e quais as possíveis relações entre tais mudanças e o modo borderline emergente da cultura atual.

\section{O mundo do trabalho e a cultura contemporânea}

Qual o significado do trabalho na atualidade?

Assim, ele não é apenas meio de satisfação das necessidades básicas, é também fonte de identificação e de autoestima, de desenvolvimento das potencialidades humanas, de alcançar sentimento de participação nos objetivos da sociedade. Trabalho e profissão (ainda) são senhas de identidade (Navarro; Padilha, 20o6, p. 14).

O trabalho sempre teve um importante significado para a constituição do sujeito na sociedade. De forma muito marcada, é ele que dá um sentido à vida. Entre tantos fatos encontrados na história da constituição do mundo trabalho, podemos citar que os sobrenomes vinham do que as famílias tinham como ofício, característica física e origem - por exemplo, Ferreira, Longo e Lisboa, respectivamente.

Segundo Muchinsky (2004), o status profissional desempenha um papel importante no senso de identidade, autoestima e bem-estar psicológico de uma pessoa. 0 trabalho é a característica central e definidora da vida da maioria dos indivíduos, o que culturalmente constitui a vida do sujeito adulto. Espera-se que, nessa fase, o sujeito cumpra, conforme fala Levy (2001), tarefas evolutivas. Entre as sete tarefas evolutivas citadas pelo autor, duas são relevantes para este ensaio: o desenvolvimento de um sentido do self e do outro - a terceira individuação, com busca do preenchimento das lacunas deixadas pelas duas outras (infância e adolescência); e a permissão de separação psicológica dos pais da infância, junto de uma (relativa) autossuficiência no mundo adulto, que facilita a relação de reciprocidade com os pais.

Foi nesta busca que o mundo do trabalho configurou-se e vem sendo ressignificado com o passar do tempo. Se antes a busca era por um trabalho onde se permaneceria por quase toda a vida, hoje o objetivo da busca não é tão claro e definido.

O mundo do trabalho se estruturou inicialmente pelo Taylorismo (1911) e Fordismo (1914), que tinham como foco a racionalização da produção e a maximização dos lucros. Posteriormente, foram substituídos pelo Toyotismo. Entendemos que é necessário fazer uma breve referência a tais ideias para refletirmos sobre a emergência de novas formas de subjetivação, emergentes da reestruturação produtiva e seus desdobramentos na atualidade. ${ }^{2}$

O Taylorismo foi criado em 1911 por Frederick Taylor e buscava reinventar a forma de trabalho adotada pelas fábricas da época. 0 princípio básico desse sistema era a eficiência no trabalho. Taylor propunha que o trabalho, antes realizado do início ao fim pelo mesmo funcionário, pudesse ser dividido em etapas de produção, em que um funcionário no processo produtivo de um carro, por exemplo,

2 Reestruturação produtiva "caracteriza-se por investimentos de capital intensivo, por meio de novas tecnologias microeletrônicas na produção e por novos padrões de gestão da produção capitalista para garantir qualidade e competitividade.” (Corrêa, 1997, p. 204) 
fosse responsável apenas pela produção de uma engrenagem. Para ele não importava o funcionário ter conhecimento da construção do produto final.

O taylorismo não promoveu mudanças importantes na base técnica do processo de trabalho, sua preocupação foi com o desenvolvimento dos métodos e organização do trabalho. Ele aprofundou a divisão do trabalho introduzida pelo sistema de fábrica, assegurando definitivamente o controle do tempo do trabalhador pela gerência, o que significou uma separação extrema entre concepção e execução do trabalho (Navarro; Padilha, 20o6, p. 17).

Henry Ford, dono de uma fábrica automobilística, buscou implementar o sistema de Taylor em seu ambiente fabril. Com o passar do tempo, Henry criou um sistema em que havia três princípios básicos: intensificação, economia e produtividade. Com isso, Ford constituiu o modelo que seria historicamente associado ao seu nome: o Fordismo, que apesar de ser um sistema novo, herdava muito do Taylorismo.

Nesse sistema, o que ditava o ritmo do trabalho eram as máquinas, visto que o funcionário ficava parado, aguardando que a máquina trouxesse-lhe o trabalho. Além disso, e ao contrário de Taylor, Ford acreditava no incentivo salarial como aliado na busca do crescimento da produção e do lucro.

O fordismo continuou requerendo este tipo de trabalhador estranhado que o taylorismo havia evidenciado. Ford mantém o essencial do taylorismo e aperfeiçoa o método introduzindo a linha de montagem e um novo modo de gerir a força de trabalho, com destaque aos incentivos dados aos trabalhadores através de aumento dos níveis salariais (Navarro; Padilha, 20o6, p. 17).

O Fordismo tem início no ano de 1914. Esse sistema de trabalho tinha como foco a automatização das linhas de produção através das linhas de montagem, o que gerou um grande reconhecimento na época, principalmente em indústrias automobilísticas. No segundo pós-guerra, esse modelo encontrou seu auge, passando a ser questionado nos anos 1970. O declínio do Fordismo começa, principalmente, pela crítica ao mecanicismo imposto às pessoas e aos processos de produção.

Esses dois sistemas de trabalho - Taylorismo e Fordismo - tinham como foco a racionalização da produção e, portanto, do trabalho e da maximização dos lucros.

Após a Segunda Guerra Mundial, surgiu nas fábricas da Toyota no Japão o Toyotismo, também chamado na época de movimento de Reestruturação Produtiva. Segundo Navarro e Padilha (2007), na Toyota de Ohno, o conceito de economia é indissociável da busca da "redução de efetivos" e da "redução de custos". Evidentemente não se pensou nos altos custos psicossociais dessa política.

Esse sistema de trabalho, ao contrário dos demais, estabelece o conceito da "Qualidade Total". Nesse viés, os funcionários são responsáveis pela qualidade integral do que produzem, buscando obter a consciência de que a produção final é de responsabilidade coletiva. Se antes os funcionários eram altamente mecanizados, aqui eram incentivados a se tornarem sujeitos do que produziam: nascem, então, os multiprofissionais e os especialistas.

Conforme dizem Navarro e Padilha (2007, p. 16) "nenhuma outra epidemia se realizou tão desgraçadamente como a da sociedade do trabalho". A dimensão crucial da glorificação do trabalho deu-se com o surgimento da fábrica mecanizada, que aparecia aos olhos do mundo ocidental como a nova ilusão de que não haveria limites para a produtividade humana.

O Toyotismo trouxe principalmente a ideia de responsabilização pelo o que se faz. Não há mais o chefe vertical. Com esse novo mecanismo, as pessoas devem se apropriar dos processos, buscando, além da produção em si, estar sempre disponível e proporcionar melhorias que beneficiem o ambiente de trabalho. Essa proposta, inclusa no dito capitalismo flexível, parece inicialmente uma porta para a autonomia; no entanto, outras formas de controle estão estabelecidas. Ao se sentir responsável, o sujeito incorpora o controle, e, por muitas vezes, a produtividade aumenta - afinal ele acaba por trabalhar dez ou quinze horas por dia.

Segundo Deluiz:

Os elementos das novas práticas de gestão que configuram o modelo da competência no mundo 
do trabalho são a valorização dos altos níveis de escolaridade nas normas de contratação; a valorização da mobilidade e do acompanhamento individualizado da carreira; novos critérios de avaliação que valorizam as competências relativas à mobilização do trabalhador e seu compromisso com a empresa; a instigação à formação contínua; e a desvalorização de antigos sistemas de hierarquização e classificação, ligando a carreira ao desempenho e à formação (Deluiz, 1995, p. 2).

Analisando esses três sistemas básicos, podemos verificar que a busca era voltada para a produção. Hoje, no entanto, o consumo é efêmero: produz-se muito, e o desejo é que se compre cada vez mais, numa busca desenfreada de possuir e descartar. Segundo Navarro e Padilha (2007), nas sociedades contemporâneas, o uso perde valor para a troca; os produtos não são mais produzidos prioritariamente para serem usados até o fim. É uma tendência que se acentua nas sociedades capitalistas, nas quais a descartabilidade e a obsolescência das mercadorias é cada vez mais prematura.

Penso que é sob essa perspectiva que Antunes (apud Moreira; Maciel; Araújo, 2006) aponta os vários significados do trabalho no decorrer da história humana, salientando que desde a antiguidade o trabalho possui um duplo sentido: expressão de vida e degradação; criação e infelicidade; atividade vital e escravidão; felicidade social e servidão.

Se refletirmos sobre o que foi dito até aqui, especialmente essa última referência a Antunes (2005), muitos elementos remontam àquilo que podemos chamar de "modo borderline de vida e sofrimento" - pensando aqui o trabalho e a inserção no mundo como uma linha de desejo e insatisfação. O sujeito sente-se parte do mundo ao inserir-se no mundo do trabalho, mas pode acabar se defrontando com sentimentos de menos valia e esvaziamento de sentido. Ele pode, inclusive, sentir-se sujeito pensante diante de uma nova tecnologia, por exemplo, mas em questão de minutos essa tecnologia pode ser substituída por outra, e, então, é possível que seus conhecimentos não mais façam sentido no novo contexto. 0 mundo do trabalho não se torna, em certa medida, sob esse ponto de vista, um mundo do trabalho border?

Nessa nova ordem, o indivíduo é submetido a uma realidade massacrante: levado a buscar formas de estar no mundo, cada vez mais efêmeras, acaba por vislumbrar um ideal de realização pessoal que se encontra longe das conquistas internas, primando, desta forma, pelas superficialidades externas que lhes são mais acessíveis e que preenchem este vazio que lhe assola de maneira menos dolorosa (Moreira; Maciel; Araújo, 20o6, p. 46).

Podemos dizer que esse é o significado do trabalho na contemporaneidade: segue sendo um dos principais meios de convívio e inserção no mundo adulto, ao mesmo tempo que é progressivamente precarizado e cada vez mais instável. Por outro lado, as formas de trabalho foram alteradas ao longo do tempo, deslocando-se cada vez mais do polo da produção para o polo do consumo. 0 resultado do trabalho hoje tem como finalidade ser descartado, e cada vez menos o sujeito é protagonista do que produz. A isso estão associadas muitas formas de sofrimento psíquico, que não são objeto direto de discussão neste trabalho, mas evidentemente massacram coletivos de trabalhadores inscritos no mundo "flexível" e "reestruturado" da produção capitalista. Os meios pelos quais o trabalho é feito em muitos casos é substituído por máquinas; os sujeitos, no entanto, permanecem buscando pertencer a algo que lhes dê sentido à vida. ${ }^{3}$

Segundo Araújo e Sachuk (2007, p.54), "novas tecnologias e formas de gerenciamento na produção promovem o aumento da produtividade e eliminam com a automação, postos de trabalho, gerando o chamado desemprego tecnológico". Nessa nova constituição, o mundo do trabalho torna-se ainda mais "border": o sujeito deve vencer a si mesmo, estar constantemente excitado, produzir cada vez

3 Destacam-se neste sentido, em interface com os estudos da Psicanálise e da Ergologia, respectivamente, os estudos de Dejours (1992; 1999) e Clot (2006). 
mais, buscar compulsivamente o reconhecimento alheio e ainda superar o desenvolvimento tecnológico.

\section{O modo borderline e o mundo do trabalho}

"Por meio do trabalho, um dos fatores mais importantes da existência humana, o homem se relaciona com a sociedade, com a prática social e consigo mesmo."

Romilda de Araújo e Maria Iolanda Sachuk

Nesta seção discutimos como essa condição borderline e o mundo do trabalho contemporâneo encontram-se e convivem. A reflexão busca compreender principalmente o quanto esse mundo do trabalho se beneficia desse tipo de funcionamento psicossocial, e ainda como, na mesma via, a sociedade constrói essa configuração.

O borderline só pôde se tornar, na atualidade, uma ideia dominante em virtude do movimento social de desrepressão. Onde podemos didaticamente melhor visualizar este movimento é na passagem do capitalismo de acumulação que desestimulava o consumo (contenção do desejo, repressão) e estimulava a poupança, para o capitalismo de consumo que desestimula a poupança e estimula o consumo (liberação e incitação do desejo) (Armony, 2013c, p. 2).

Após a ressalva sobre a construção desse ensaio, julgo pertinente abordar o fator "tempo", uma das mais fortes alavancas da minha reflexão. Talvez o leitor se pergunte como o tempo relaciona-se ao tema central deste escrito, mas, assim como foi necessário falar dos tipos bordere dos sistemas de trabalho, essa abordagem é relevante à conclusão desta escrita.

Como citado no capítulo anterior, nos anos 1970, 1980 e em boa parte dos anos 1990, os sujeitos entravam em uma empresa onde muito provavelmente permaneceriam pelo resto de suas vidas produtivas; aliás, era estranho se alguém ali não permanecesse. Hoje, no entanto, percebemos que as relações de trabalho são pouco duradouras, advento que foi fortalecido pela tão propalada Geração Y - que será tratada adiante.

Esse curto prazo é exercido por duas vias: o perfil das empresas de hoje é construir estruturas em que os sujeitos saibam que podem ser substituídos a qualquer momento. Estes, por sua vez, preparam-se para poder ter um currículo suficiente a fim de que possam, caso necessário, migrar para outra empresa.

“Não há longo prazo" é um princípio que corrói a confiança, a lealdade e o compromisso mútuo. A confiança pode, claro, ser uma questão puramente formal, como quando as pessoas concordam numa transação comercial ou dependem de que as outras observem as regras de um jogo (Sennett, 2009, p.24).

Um perfil muito neurótico tem dificuldade de se adaptar às empresas da atualidade. É necessário não se envolver de forma tão enraizada como anteriormente, pois as tão faladas adaptabilidade e flexibilidade são colocadas à prova diariamente.

Atualmente não é esperado que se permaneça em uma empresa por vinte anos, espera-se que as pessoas possuam capacidade de adaptação às novidades que esse novo mundo pode trazer. Acredito que, se entrevistarmos os jovens desta geração, uma carreira de longo prazo para eles seja de no máximo cinco ou seis anos em uma grande empresa.

Segundo Sennet (2009), um jovem norte-americano com pelo menos dois anos de faculdade pode esperar mudar de emprego pelo menos onze vezes no curso do trabalho, e trocar sua aptidão básica pelo menos outras três durante esses quarenta anos. A partir disso o fator "liberdade" também pode ser repensado. Ao falar das novas formas de liberdade através do sistema imposto pelo capitalismo, o autor considera que a repulsa à rotina burocrática e a busca pela flexibilidade produziram novas estruturas de poder e controle, ao invés de criar em as condições que nos libertam.

Pensemos aqui em uma grande empresa. Nela existem níveis operacionais e níveis gerenciais. Em termos de liberdade, em qual desses níveis julgar-se-ia haver mais presença dessa condição? É claro que no nível gerencial. Neste caso, então, seriam as pessoas mais felizes em seu trabalho? Sennet (2009) questiona: uma estrutura de caráter bastante diferen- 
te surge entre os que exercem o poder dentro desse complicado regime moderno. Eles são livres, mas é uma liberdade amoral. Podemos entender "liberdade amoral" através dos laços fracos que nela são estabelecidos. 0 preço que se paga por essa liberdade nos modelos da contemporaneidade pode ser alto: não se sabe em que momento essa condição poderá ser interrompida. É uma espécie de controle velado. Pensa-se que a liberdade existe, no entanto, o que existe são outras formas de controle.

E como o modo borderline se insere neste contexto? Por que o mundo do trabalho é beneficiado e construído através dele?

O borderline pensado na perspectiva edípica será falado como tendo um superego frouxo, lábil, influenciável, correspondente à descrição freudiana do superego feminino. Justamente é este superego poroso - que se deixa penetrar e influenciar - que privilegiará o homem da pós-modernidade, tornando-o apto a acompanhar as rápidas transformações da cultura. (Armony, 2013c, p. 6)

Em um ambiente onde a linha de bordo da confiança está sempre se fazendo presente, características como uma constituição porosa de si, ou seja, uma constituição que se permite ser penetrada, não é conveniente? Perfis predominantemente neuróticos conseguiriam se estabelecer nas empresas da atualidade? Penso que não.

O mundo do trabalho pede e se constitui de pessoas que buscam, cada vez mais, maior remuneração e reconhecimento. A vida laboral do sujeito, diferente de outras épocas, está nas mãos dele próprio. Essas possibilidades de experimentação e flexibilização identitárias pode, como tudo, ter o seu lado positivo e negativo. Segundo Armony (2013b), o homem pós-moderno mais vive, mais experimenta a vida do que a padroniza em comportamentos repetitivos e lugares estanques. O homem moderno mais pretendia viver no espaço objetivo; o homem contemporâneo sente-se mais à vontade no espaço potencial, no jogo entre fantasia e realidade.

É bem verdade que as empresas beneficiam-se do modo borderline, mas é também verdade que os sujeitos de hoje buscam formas de trabalho muito diferentes das almejadas anteriormente. Por causa desses fatores, temos a flexibilização do trabalho, que apresenta tanto o crescimento de empresas de serviços, de novas formas de trabalho, como o crescimento de pessoas que trabalham em casa, por causa do advento da internet, por exemplo. 0 que percebemos, em última análise, é uma mudança de paradigma. Vale ressaltar que essa não é uma mudança em andamento: já é realidade em nosso dia a dia e também pode estar presente nos atendimentos psicológicos.

Esta inédita flexibilização do trabalho no mundo contemporâneo é expressa pelo crescimento do terceiro setor, o de serviços. As instituições fabris, os contratos regulares e a dicotomia entre tempo de vida e tempo de trabalho, características do regime de produção fordista, tendem a se torna cada vez mais fluidas, fragmentadas (Laureano, 2012, p. 49).

As novas configurações de trabalho citam com frequência a flexibilidade que, para Sennett (2009), designa a capacidade de ceder e recuperar-se da árvore, o teste e a restauração de sua forma. Em termos ideais, o comportamento humano flexível deve ter a mesma força tênsil: ser adaptável a circunstâncias variáveis, mas não quebrado por elas. Ou seja, a mesma flexibilidade ditada pelas configurações de trabalho, que envolvem horários e formas de desempenhar o mesmo, por exemplo, exige, na via contrária, sujeitos com a mesma habilidade: não importa o que aconteça - você deve estar preparado para enfrentar!

Esse tipo de comportamento é muito discutido na atualidade através da famosa Geração Y, caracterizada pela facilidade de aprender, pelo não reconhecimento de uma hierarquia vertical (como aprendido nas fábricas anteriormente) e pela busca incessante de crescimento num contexto cada vez mais competitivo. Essa também é o alvo do mundo do trabalho contemporâneo.

A maioria desses jovens busca algo não tão almejado por seus antecessores: a qualificação constante. Neste panorama reflito, como exemplo, o crescimento dos intercâmbios. Se antes o movimento era feito dentro da empresa - de uma mesa ou de uma sala -, hoje o movimento é feito para fora dela: novos países, novas línguas, novas tecnologias. 
Sendo assim, é por meio do trabalho que o homem se autoproduz: desenvolve habilidades e imaginação, aprende a conhecer as forças da natureza e a desafiá-las, conhece as próprias forças e limitações, relaciona-se com os companheiros e vive o afeto de toda relação, impõe-se uma disciplina (Araújo; Sachuk, 2007, p. 56).

O trabalho é o meio pelo qual o sujeito modifica o ambiente em que vive e encontra sentido para a vida. Aqui retomo novamente a ideia central de um trabalho que constitui e é constituído em um movimento cíclico: se o sujeito encontra sentido na vida por meio do trabalho, e o trabalho parece-nos na atualidade muito próximo das características desse modo borderline de vida e sofrimento, não se pode julgar "normal" essa população que vive na linha de bordo, que vive no fio da navalha?

Nessa nova configuração do mundo do trabalho e da constituição da sociedade, após examinar pesquisa desenvolvida pelo Governo Federal, através da Secretaria de Assuntos Estratégicos da Presidência da República (SAE/PR), com o apoio do Instituto de Pesquisa Econômica Aplicada (Ipea), de 2013, intitulado "Juventude levada em conta", acho importante ressaltar o quanto o público jovem é o maior atingido por essas novas constituições, pois "em uma economia com oferta limitada de postos de trabalho, quanto maior a juventude maior a concorrência pelos limitados postos existentes e, portanto, maior a taxa de desemprego e menores as remunerações" (SAE/ $\mathrm{PR}, 2013$, p. 35). Segundo a pesquisa realizada pelo Ipea, são 51 milhões de pessoas consideradas jovens hoje no Brasil (entre 15 e 29 anos), correspondendo proporcionalmente a $26 \%$ da população brasileira.

Considerando a efemeridade a tão falada característica da juventude, como constituir-se sujeito do mundo adulto em um mundo do trabalho onde não há grandes chances para o crescimento gradual? E como não pensar nessa nova normalidade borderline tão paradoxal, que de um lado é valorizada e desejada, mas que, de outro, é produtora de vazio e falta de sentido? Como buscar encontrar sentido em um espaço em que a confiança é extremamente frágil? É a partir desses questionamentos que podemos nos encaminhar para a finalização deste ensaio.

\section{Considerações finais}

Considerando o exposto, iremos nesta última seção pautar a implicação do psicólogo nessas configurações de mundo.

Primeiramente, é relevante ressaltar a importância desse novo olhar para o modo borderline, entender que não se trata apenas de um diagnóstico: na sociedade contemporânea é um também um modo de vida incorporado ao dia a dia.

O borderline acopla-se melhor à sociedade pós-moderna por sua maior flexibilidade, por não possuir uma identidade firme, por não possuir um superego sólido. Existe uma afinidade entre a sociedade pós-moderna e o borderline, o que é uma redundância, pois simplesmente o borderline faz parte dessa sociedade. As empresas já não querem funcionários disciplinados e burocráticos, mas homens criativos. A escola já não fala em disciplina, dever e decoreba, mas sim em criatividade, pesquisa, singularidade, estimulação afetiva (Armony, 2013c, p. 7).

Como apontado pelo Ipea, a população jovem representa grande parte da população brasileira, e são essas as pessoas que constituem e constituirão as organizações e o mundo do trabalho nos próximos vinte ou trinta anos. Por consequência, é exatamente este o público mais atingido pelas novas formas de vida, que se desloca da normoneurose para o espectro borderline.

No mundo do trabalho, atualmente (assim como na vida) não há garantias, não há carreiras e caminhos a serem seguidos com total segurança. Não há aprendizados que durem para sempre e as relações são cada vez mais superficiais. É nesse meio que nossos pacientes estão inseridos, o que certamente reflete nos atendimentos clínicos e que deve compreender nossa atenção na compreensão dos casos. "Na sociedade atual, onde tudo se transforma e novos valores são rapidamente consumidos e substituídos por outros que serão também logo desmanchados, o nível de angústia tende a aumentar por causa da insegurança gerada pelas contínuas mudanças" (Hegenberg, 2013, p.17).

Certamente que o novo regime solicitado pelas organizações é, de fato, interessante em alguns 
aspectos, mas é necessário ter cuidado com o paradoxal sentimento de onipotência/vazio imposto por tal regime. A proposta de encarar formas de trabalho flexíveis traz consigo necessidades que, na maioria das vezes, não são promotoras de saúde: a necessidade de estar atento a si e aos outros, a busca pelo prazer no trabalho chocando-se com a busca incessante por reconhecimento e crescimento. A citação de Sennett (2009), em A corrosão do caráter, traz-nos ainda mais características sobre essa relação que em nada remete às relações de confiança que pareciam existir anteriormente. Um regime flexível tem ainda uma terceira característica: as mudanças nas redes, nos mercados e na produção de que -utiliza permitem o que parece ser um paradoxo: a concentração de poder sem sua centralização.

O que se estabelece, quase que integralmente, é esse jogo de pertencer, e, no próximo minuto, não mais. Por esse motivo, a sintonia entre o modo borderline de existir e o trabalho na contemporaneidade é também uma linha de bordo, que pode representar uma maior abertura para formas mais criativas e vigorosas de existência, mas, por outro lado, pode resultar em formas muito mais sofisticadas de exploração e sofrimento no trabalho. Se anteriormente a alienação dos trabalhadores era dada pelo trabalho repetitivo nas esteiras, hoje é representada ainda mais pela desejada flexibilidade e desestruturação. Se anteriormente, conforme Sennett (2009), o controle era estabelecido instituindo-se metas de produção ou lucro para uma ampla variedade de grupos na organização, hoje a meta é feita a partir da demanda de produtos entregues e do desempenho individual.

É relevante citar que a intenção aqui não é, de forma alguma, rejeitar integralmente as relações de trabalho contemporâneas. Defendemos inclusive que é o trabalho um dos mais importantes elementos de constituição do sujeito, mas é preciso entender os movimentos que ocorrem na atualidade, sobretudo quando se pensa no papel do psicólogo como agente de promoção da saúde coletiva.

Segundo Araújo e Sachuk (2007, p. 6), o trabalho é uma das atividades com a qual o homem altera a natureza para melhor satisfazer suas necessidades. É nesse sentido que o trabalho do psicólogo deve ser conduzido: compreendendo e discutindo essas novas configurações, mas aceitando o fato de que o trabalho estará sempre presente na vida do sujeito, como importante forma de dar sentido à própria existência.

A população jovem, entretanto, merece um cuidado especial. São esses sujeitos que encontraremos nos serviços de saúde, nas clínicas, nas escolas e nos ambientes organizacionais. Portanto é essencial uma abertura para a compreensão dessas novas produções de sentido na vida e no trabalho.

Assim, podemos afirmar que o mundo do trabalho na contemporaneidade é ao mesmo tempo efeito e força constitutiva das novas formas de existir e conviver. Se, por um lado, a flexibilização do trabalho representa possibilidade de criação e abertura para novas formas de vida, por outro, pode ser também ela uma forma de aprisionamento nos ideais de uma cultura de consumo cada vez mais narcísica e vazia de sentido. Fica a nós, psicólogos, e tantos outros profissionais da saúde, o desafio de construir práticas onde os sujeitos se empoderem de suas escolhas e de seus caminhos, fazendo do trabalho um campo de produção de sentidos.

\section{Referências}

ARAÚJO, R. R. de; SACHUK, M. I. Os sentidos do trabalho e suas implicações na formação dos indivíduos inseridos nas organizações contemporâneas. Revista de Gestão USP, São Paulo, v. 14, n. 1, p. 53-66, 2007. Disponível em: <http://www.revistasusp.sibi.usp.br/pdf/rege/ v14n1/v14n1a5.pdf >. Acesso em: 27 mar. 2014.

ARMONY, N. Borderline: uma outra normalidade. Rio de Janeiro: Revinter, 2010.

ARMONY, N. O homem transicional. São Paulo: Zagodoni, 2013a.

ARMONY, N. Borderline e espaço potencial winnicottiano. In: . O homem transicional. São Paulo: Zagodoni, 2013b. p. 51-66.

ARMONY, N. Borderline, identificação e subjetividade pós-moderna. In: O homem transicional. São Paulo: Zagodoni, 2013c. p. 67-74. ARÓS, A. C. S. P. de C.; VAISBERG, T. M. J. A. Clube da luta: sofrimentos radicais e sociedade 
contemporânea. Psicologia: teoria e prática, São Paulo, v. 11, n. 2, p. 3-16, 2009.

BAUMAN, Z. Tempos líquidos. Rio de Janeiro: Jorge Zahar, 2007.

BAUMAN, Z. Medo líquido. Rio de Janeiro: Jorge Zahar, 2008.

BRASIL. Secretaria de Assuntos Estratégicos da Presidência da República. A juventude levada em conta. Brasília, DF, 2013. Disponível em: <http:// www.sae.gov.br/site/wp-content/uploads/JuventudeLevada-em-Conta.pdf>. Acesso em: 16 jun. 2014.

CORREA, M. B. Reestruturação produtiva e industrial. In: CATTANI, A. D. (Org.). Trabalho e tecnologia: dicionário crítico. Petrópolis: Vozes, 1997. p. 202-203.

CLOT, Y. A função psicológica do trabalho. Rio de Janeiro: Vozes, 2006.

DEJOURS, J. C. A loucura do trabalho: estudo de psicopatologia do trabalho. 5. ed. São Paulo: Cortez, 1992.

DEJOURS, J. C. A banalização da injustiça social. Rio de Janeiro: Fundação Getúlio Vargas, 1999.

DELUIZ, N. O modelo das competências profissionais no mundo do trabalho e na educação: implicações para o currículo. Boletim Técnico Senac, Rio de Janeiro, v. 27, n. 3, 2001. Disponível em: <http://www.senac.br/ informativo/bts/273/boltec273b.htm>. Acesso em: 12 maio 2014 .

HEGENBERG, M. Borderline. São Paulo: Casa do Psicólogo, 2013. (Coleção Clínica Psicanalítica. Volume IV.).

FIGUEIREDO, L. C. Confiança: a experiência de confiar na clínica psicanalítica e no plano da cultura. Revista Brasileira de Psicanálise. São Paulo: Febrapsi. v. 41, n. 3, p. 69-87, Set., 2007.

FOUCAULT, M. Doença mental e psicologia. Rio de Janeiro: Tempo Brasileiro, 1975.

GIDDENS, A. As consequências da modernidade. São Paulo: Unesp, 1991.
GIDDENS, A.; BECK. U.; LASH, S. Modernização reflexiva: política, tradição e estética na ordem social moderna. São Paulo: Unesp, 1997.

LARROSA, J. A operação ensaio: sobre o ensaiar e o ensaiar-se no pensamento, na escrita e na vida. In: Educação \& Realidade, Porto Alegre, v. 2, n. 1, p. 27-43, 2004.

LAUREANO, P. S. Psicanálise, trabalho imaterial e pós-modernidade. Trivium: estudos interdisciplinares, Rio de Janeiro, v. 5, n. 2, p. 45-57, 2013. Disponível em: <http:// pepsic.bvsalud.org/scielo.php?pid=S217648912012000200006\&script=sci_arttext $>$. Acesso em: 18 abr. 2014 .

LEVY, R. $O$ adolescente. In: EIZIRIK, C. L. (Org.). O ciclo da vida humana: uma perspectiva psicodinâmica. Porto Alegre: Artmed, 2001. p. 167-179.

LINEHAN, M. Transtorno da personalidade Borderline: conceitos, controvérsias e definições. In:___. Terapia cognitivo-comportamental para transtorno de personalidade Borderline. Porto Alegre: Artmed, 2010. p. 16-31.

MINERBO, M. Ser e sofrer, hoje. Ide, São Paulo, v. 35, n. 55, p. 31-42, 2013.

MOREIRA, V.; MACIEL, R. H.; ARAÚJO, T. Q. Depressão: os sentidos do trabalho. Revista do NUFEN, Belém, v. 5, n. 1, p. 44-56, 2006. Disponível em: <http://pepsic.bvsalud.org/scielo. php?pid=S2175-25912013000100006\&script=sci arttext>. Acesso em: 2 abr. 2014.

MUCHINSKY, P. M. Psicologia organizacional. São Paulo: Thomson, 2004.

NAVARRO, V. L.; PADILHA, V. Dilemas do trabalho no capitalismo contemporâneo. Psicologia \& Sociedade, São Paulo, v. 19, n. 1, p. 14-20, 2007.

OSÓRIO, C. M. S. Adultos jovens, seu scripts e cenários. In: EIZIRIK, C. L. (Org.). O ciclo da vida humana: uma perspectiva psicodinâmica. Porto Alegre: Artmed, 2001. p. 141-156.

ROUDINESCO, E.; PLON, M. Gozo. In: Dicionário de psicanálise. Rio de Janeiro: Zahar, 1998. 
SENNETT, R. A corrosão do caráter: consequências pessoais do trabalho no novo capitalismo. São Paulo: Record, 2009.
WHO - WORLD HEALTH ORGANIZATION. CID10: classificação de transtornos mentais e de comportamento da CID-10. Porto Alegre: Artmed, 1993.

\section{Contribuição dos autores}

Todos os autores foram responsáveis pela concepção, elaboração e revisão do artigo.

Recebido: 16/10/2014

Reapresentado: 24/07/2015

Aprovado: 03/09/2015 